\author{
Ewa Knapik*, Jerzy Stopa*
}

\title{
LABORATORY EXPERIMENTS \\ FOR CRUDE OIL REMOVAL FROM WATER SURFACE USING HYDROPHOBIC NANO-SILICA AS SORBENT
}

\section{INTRODUCTION}

There are numerous clean-up techniques in a response to a spill of oil [1-5]. These include:

- bioremediation (bioaugmentation and/or biostimulation) [2];

- mechanical removal using skimmers, booms, pumps, mechanical separators;

- in-situ burning [3];

- chemically dispersing oil into the water volume;

- barriers/berms to prevent entry of oil into a protected area;

- water flushing or steam clearing to remove heavy residual oil;

- sorbents to remove oil from water surface through adsorption and/or absorption.

Selecting an appropriate response options is strongly dependent on type and amount of oil spilled, catastrophe location, spill trajectories, current and forecast weather [4]. Use of sorbents is an efficient secondary treatment method after mechanical means and for recovering small pools of oil where access is restricted. The materials used can be divided into three types [6-13]:

- synthetic products, mostly polypropylene (PP) and polyurethane;

- mineral products: perlite, exfoliated graphite, vermiculites, organoclay, zeolite, silica aerogel, diatomite, fly ash, sand;

- agricultural products and residues: rice straw, peat moss, cotton, cotton grass, corn corb, barks, milkweed, kenaf, and kapok.

Natural sorbent materials are inexpensive, biodegradable and available locally. However, some of them exhibit poor reusability and buoyancy, relatively low oil sorption

* AGH University of Science and Technology, Faculty of Drilling, Oil and Gas, Krakow, Poland 
capacity and low hydrophobicity [6]. Most of the sorbents can not be used in the raw state but require chemical or mechanical treatment. Oiled material need to be temporary stored to prevent damage from insects, microorganisms, UV light and fire which increases the cost of disposal. Reuse of most of sorbents is impossible due to the deterioration of mechanical properties and their sorption capacity. Hereby, large amounts of waste may be generated. Adsorbed hydrocarbons may leach out providing a source of secondary contamination.

The limitations of the commercially available sorbent materials have led to the developing of alternative materials, especially nanopowders. Recently, many different techniques have been developed with the use of nanoparticles in a variety of forms and approaches (Fig. 1).

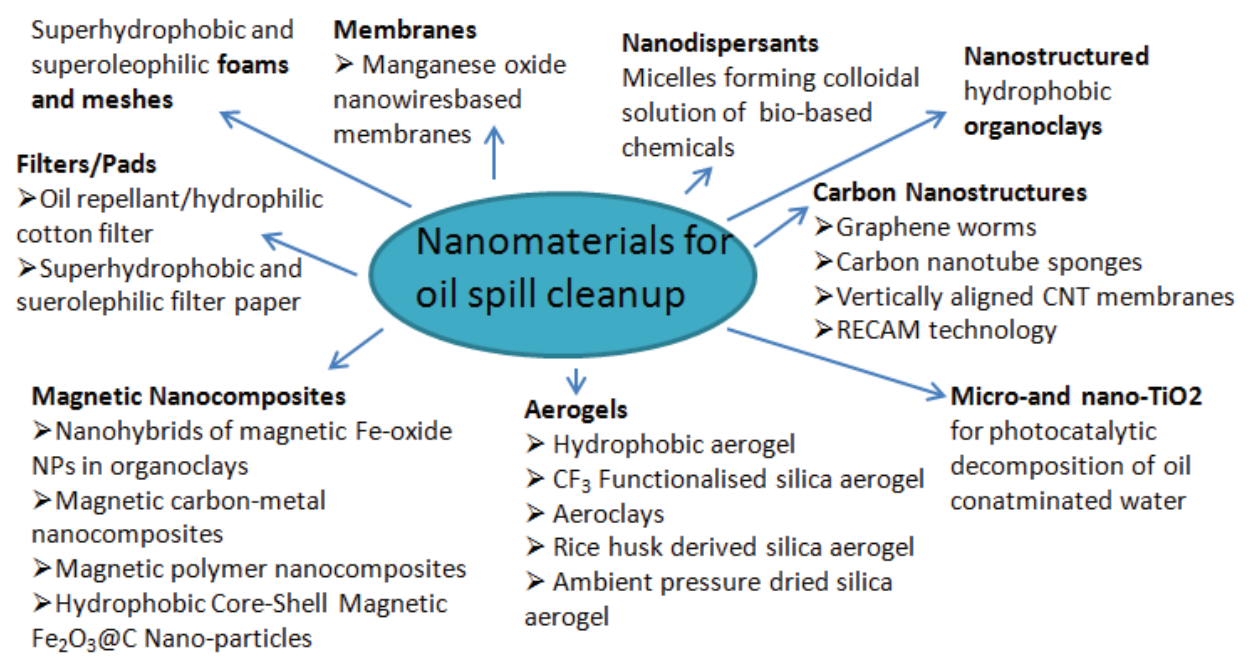

Fig. 1. Nanotechnology-based solutions for oil spills [7, modified].

In this work hydrophobic silica nanoparticles were chosen because of their possible high efficiency, chemical and mechanical stability and high surface area. Silica nanopowder is lightweight, non-allergic, non-toxic, resistant to biocorrosion and odorless.

\section{METHODSAND MATERIALS}

\subsection{Materials}

Crude oil was obtained from Świdnik and Grobla oil fields, Poland. The oil density and viscosity were measured using a pycnometer and a capillary viscometer respectively. The measurements were run at $20{ }^{\circ} \mathrm{C}$ and the mean value was $0.8199[\mathrm{~g} / \mathrm{ml}], 4.03 \mathrm{cP}$ for Grobla crude oil and 0.8787 [g/ml], 45.25 cP for Świdnik oil. Sodium hydroxide $(\mathrm{NaOH})$, 
hydrochloric acid $(\mathrm{HCl})$ and sodium chloride $(\mathrm{NaCl})$ were obtained from POCH (Poland). $\mathrm{HCl}$ nad $\mathrm{NaOH}$ were used to regulate the $\mathrm{pH}$ of water/brine. Synthetic brine was prepared by dissolving of different amounts of $\mathrm{NaCl}$ by weight in deionized water. Hydrophobic nanosilica in a powder form was purchased from Dynamic Design. Table 1 shows some physical and chemical properties of the nanopowder taken from the manufacture. All chemicals were used without further purification.

Table 1

Chemical composition and physical properties of nanosilica

\begin{tabular}{|l|l|}
\hline Average particle size $[\mathrm{nm}]$ & 15 \\
\hline BET surface area $\left[\mathrm{m}^{2} / \mathrm{g}\right]$ & $170 \pm 30$ \\
\hline Bulk density $\left[\mathrm{g} / \mathrm{dm}^{3}\right]$ & 50 \\
\hline $\mathrm{SiO}_{2}[\%$ mas.] & $\geq 99,8$ \\
\hline $\mathrm{Fe}_{2} \mathrm{O}_{3}[\%$ mas.] & $\leq 0,01$ \\
\hline $\mathrm{Al}_{2} \mathrm{O}_{3}[\%$ mas.] & $\leq 0,05$ \\
\hline $\mathrm{TiO}_{2}[\%$ mas.] & $\leq 0,03$ \\
\hline
\end{tabular}

\section{METHODS}

Contact angle measurements were performed by applying a single drop of liquid from a syringe to the surface of glass plates coated with sprayed nanosilica and photographing it immediately. Crude oil $(5 \mathrm{~g})$ was poured on the surface of the water $(100 \mathrm{ml})$ and different amounts of solid nanoparticles were gently distributed through a strainer. Nanosorbent was left for a period of 15 minutes for complete saturation with oil. It was observed that sorption process occurs immediately, so after 15 minutes an equilibrium time is reached. Samples were filtered on stainless steel wire mesh and the slurry was weighted to evaluate the effectiveness of the removal of hydrocarbons. Effect of $\mathrm{pH}$ and salinity on the sorption capacity of nanosorbent was evaluated at a mass ratio of water/oil /nanoparticles fixed at 100/5/0.6 using Grobla oil.

\section{RESULTS}

Glass surface coated with nano-silica showed a very high superhydrophobicity with the water contact angle of $135^{\circ}$ (Fig. 2a). When crude oil was placed on the superhydrophobic surface it adsorbed so quickly that the droplet was impossible to photograph. The ability of a material to repel the water provides a high buoyancy and low water uptake. The unsinkable property of pure nanoparticles is shown in Fig. 2b. Furthermore, the nanopowder after oil adsorption also floats on the water surface (Fig. 2c). 
a)

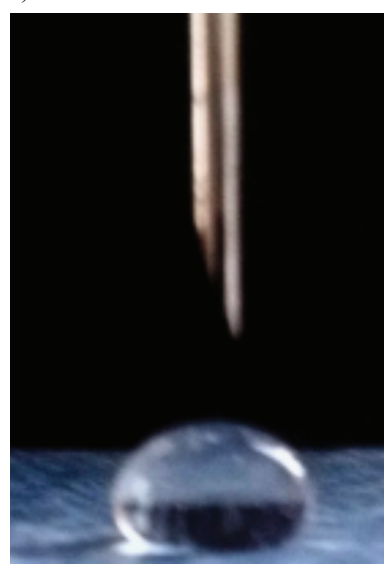

b)

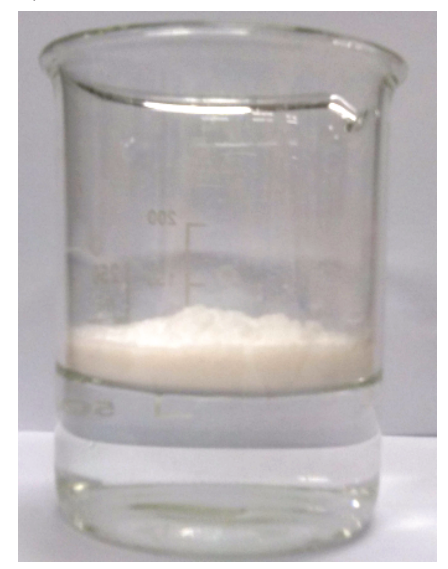

c)

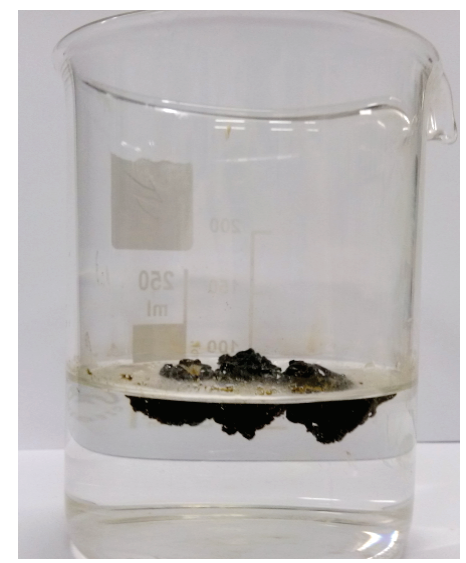

Fig. 2. Contact angle between water and the surface modified with nanoparticles (a), nanopowder placement on the water surface (b), oil-water mixture after nanopowder addition (c)

The influence of sorbent mass on sorption efficiency during removal of two types of crude oil from water is shown in Fig. 3.

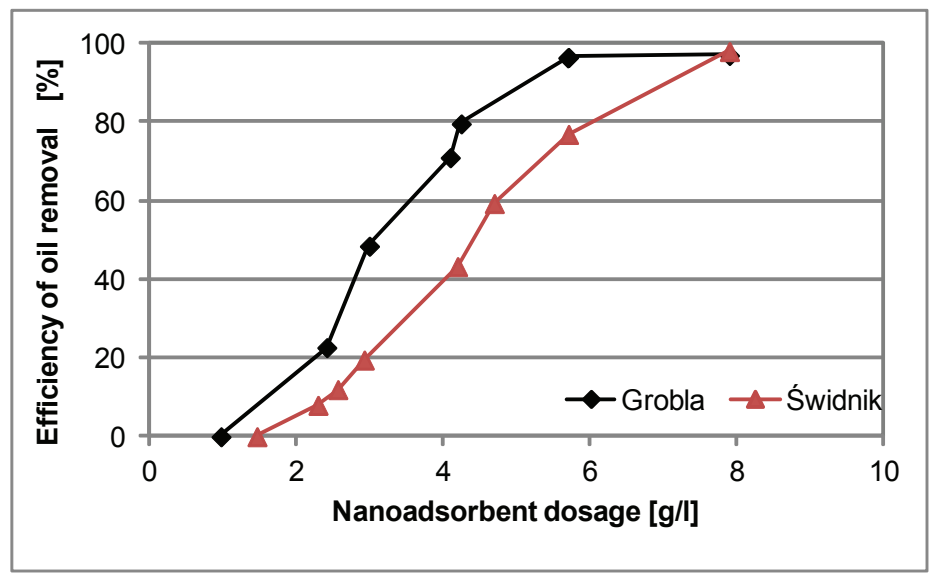

Fig. 3. Influence of nano-silica dosage on the contaminant removal efficiency

Efficiency of oil removal increases with rise in sorbent mass until it reaches a constant value of $99 \%$ and $96 \%$ for Grobla oil and Świdnik oil respectively. For a small dosage of the adsorbent (less than $0.2 \mathrm{~g}$ per $100 \mathrm{ml}$ oily water) resulting slurry was sticky and the adsorbed oil leaches out. Higher doses of nanoparticles permanently bind the oil which facilitates the storage and transport of waste material. The structure of the sorbent with varying oil content is shown in Fig. 5 a-b. 
Adsorption is caused by van der Waals force and it is not very specific. Rapid formation of agglomerates results in the capture of water in the sorbent layer. Water uptake does not affect the sorption capacity but will hinder the further processing of the sorbent.

Sorption capacity for experiments in batch conditions was determined according to the equation [8]:

$$
k=\left(C_{i}-C_{f}\right) / m
$$

where $k$ is the sorption capacity $(\mathrm{g} / \mathrm{g}), C_{\mathrm{i}}$ the initial oil concentration $(\mathrm{g}), C_{\mathrm{f}}$ the final oil concentration $(\mathrm{g})$ and $m$ is the mass of sorbent $(\mathrm{g})$.

Maximal sorption capacities were $6.0 \mathrm{~g}$ of oil/g sorbent for light crude oil and $5.85 \mathrm{~g}$ of oil/g sorbent for heavy crude oil. Adsorption efficiency can be described as:

$$
E=\left(\frac{m_{f}}{m_{i}}\right) \cdot 100 \%
$$

where $\mathrm{E}$ is the efficiency of oil removal $(\%), \mathrm{m}_{\mathrm{i}}-$ the initial oil mass in the system $(\mathrm{g}), \mathrm{m}_{\mathrm{f}}-$ the oil mass adsorbed by the nanopowder. The removal efficiency found by the gravimetric method is high as $99 \%$ and $96 \%$ for light and heavy crude oil respectively.

On the other hand, the adsorption efficiency is represented as:

$$
\frac{d E}{d x}=B \cdot\left(E_{\max }-E\right)
$$

where $\mathrm{E}_{\max }$ is the maximal possible efficiency of oil removal at equilibrium conditions, Bsorption coefficient, $\mathrm{x}$ - dosage of adsorbent ( $\mathrm{g}$ of nano-silica / 1 of oily water).

Integrating the above equation with the limit $E=0$ at $x_{o}=0$ gives:

$$
E(x)=E_{\max }\left(1-e^{-B x}\right)
$$

The experimental data and fits are shown in Fig. 4. A good agreement is seen for both types of crude oil. Removal of aromatic oil is difficult and regardless of an applied dosage of nano-silica the achieved efficiency can not be greater than 96\%. Heavy aromatic oil due to its polar nature and high viscosity harms the adsorption process. The figure 4 shows that there is a minimum dosage above which the purification is efficient. Of course, the oil sorption on nanoparticles occurs under all conditions but the separation on stainless steel wire mesh requires the formation of a stable agglomerate. In the sorption process both cohesive and adhesive forces will be observed. Due to the effects of adhesive forces, liquid wet the surface forming a thin, relatively uniform film over the surface. Cohesive forces between oil molecules hold the liquid together thereby opposing spreading on the solid surface. For low dosage of a dusty adsorbent the cohesion will facilitate the dispersion of hydrophobic particles in the oil, without formation of a separate solid phase which hinders further separation. The minimum dose of sorbent for the considered systems is about $2 \mathrm{~g} / 1$. 


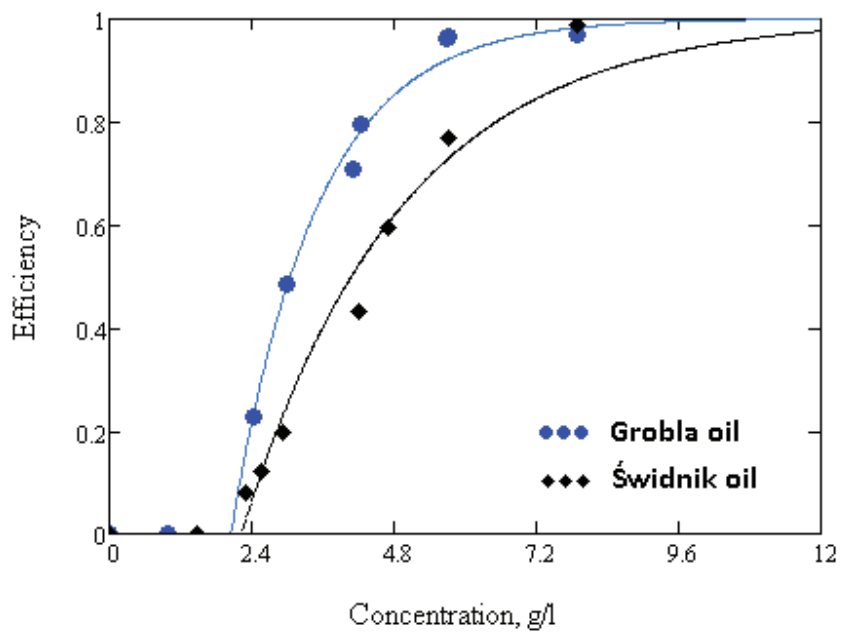

Fig. 4. Adsorption isotherms for different types of crude oil on nanoparticles

The reusability of sorbent is poor. The slurry after sorption was dissolved in chloroform and centrifuged to recover the sorbent. The evaporation residue has a completely different structure [Fig. 5c], the sorbent is glued, petrified and requires a mashing.

a)

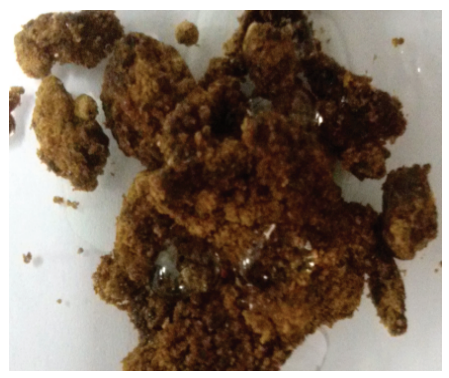

b)

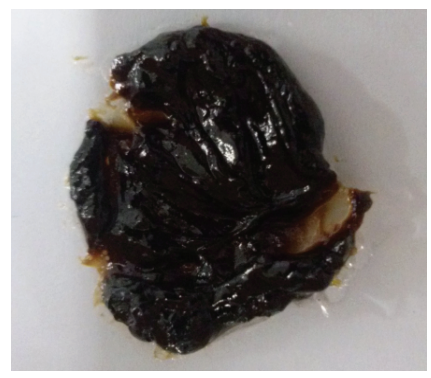

c)

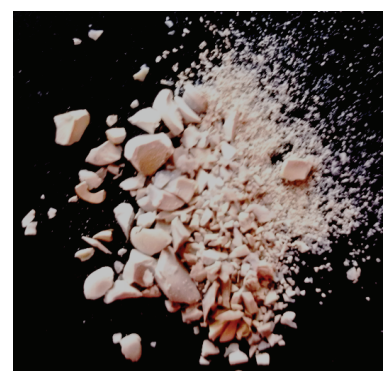

Fig. 5. An accidental water uptake during oil sorption due to agglomerates formation (a), a viscous and bulky structure of the sorbent with an excess oil (b), sorbent deterioration after oil desorption (c)

Silica nanopowder exhibits good oil retention ability. The collected slurry does not drain even at elevated temperatures which greatly facilitates transport and prevents recontamination. A great advantage of oily nanoparticles is their ability to float on the water surface in the form of a viscous stable layer that is easily removed from the surface by skimmig. This prevents the dispersion of oil in the water column and the spreading of nanoparticles by the wind. The salinity and $\mathrm{pH}$ changes [9 - 11] slightly affect the sorption capacity of nanosorbent which is important due to the possibility of their application in marine environment. 
A higher salinity (due to the large density difference between the oil and the brine) leads to an easy phase separation and therefore to a more efficient water purification (Fig. 6.).

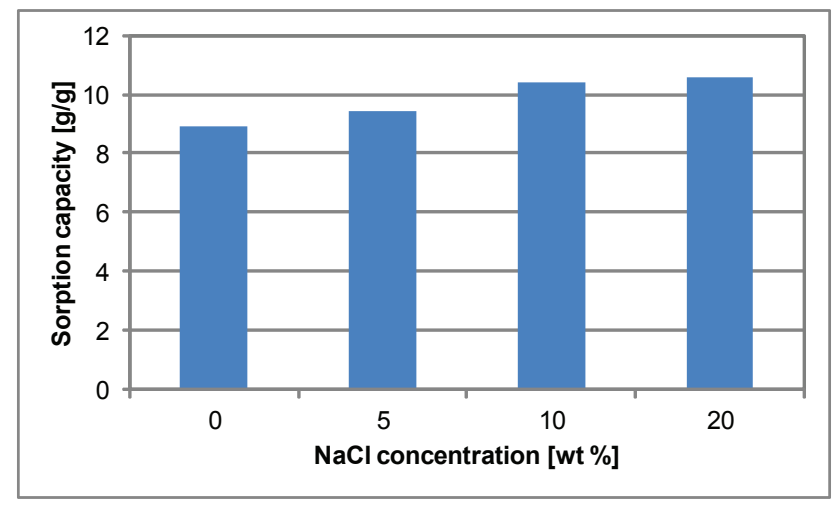

Fig. 6. Impact of salinity on the sorption capacity of nano-silica

Efficiency of oil removal with nano-silica was increased with increasing $\mathrm{pH}$ value which is related to surface energy changes and emulsion breaking. An acidic condition promotes destabilisation and coalescence of oil droplets what enhances the sorption process. Saponification process in a basic environment leads to carboxylic acid salts formation. These compounds are natural surfactants and enhance the dispersibility of crude oil.

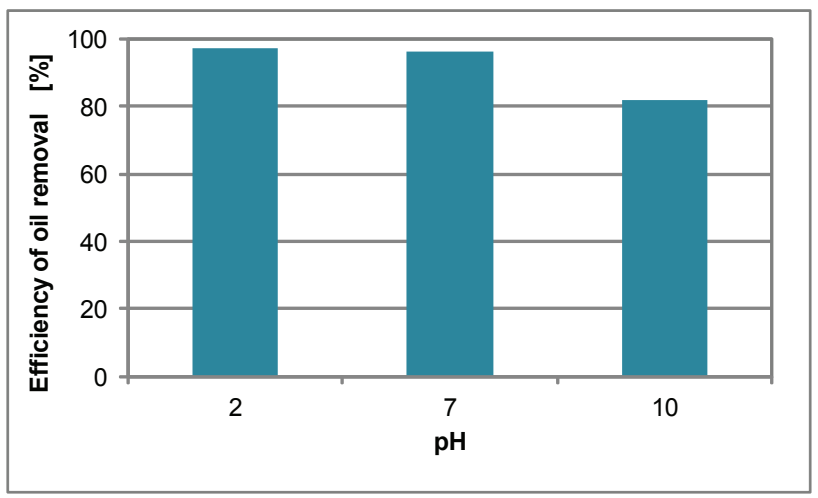

Fig. 7. Effect of $\mathrm{pH}$ on efficiency of oil removal with silica nanosorbent

\section{CONCLUSIONS}

Silica nanopowders was found to be suitable for permanent oil removal from the water surface. Separation efficiency was over $95 \mathrm{wt} \%$ for both investigated crude oils. Sorption capacity of nano-silica powder was $6.0 \mathrm{~g}$ of oil/g sorbent for Grobla crude oil and $5.85 \mathrm{~g}$ of 
oil/g sorbent for Świdnik crude oil. The contact angle with water was over $135^{\circ}$ and attest to the hydrophobicity of the silica nanoparticles. Salinity of water and $\mathrm{pH}$ changes affect the efficiency of oil absorption process. Oil adsorption from the brine is much higher than the adsorption from distilled water. The basic environment favors the emulsion formation which hamper oil spills cleanup. Further investigations should focus on the optimization of the nanosorbent properties and the development of technologies for large-scale usage.

\section{REFERENCES}

[1] Allen A., Comparison of response options for offshore oil spills. Proceedings, Artic and Marine Oil Spill Pollution, Vancouver, June 7-9, 1988, pp. 289-306.

[2] Fernandez-Alvarez, P., Vila J., Garrido-Fernandez J. M., Grifoll M., Lema J. M., Trials of bioremediation on a beach affected by the heavy oil spill of the Prestige, Journal of Hazardous Materials B137 (2006) 1523-1531.

[3] Zengel S., Michel J., Dahlin J., Environmental Effects of In Situ Burning of Oil Spills in Inland and Upland Habitats, Spill Science \& Technology Bulletin 8( 4) (2003) 373377.

[4] American Petroleum Institute (API), National Oceanic and Atmospheric Administration (NOAA), U.S. Coast Guard (USCG), and U.S. Environmental Protection Agency (EPA). In press. Environmental Considerations for Marine Oil Spill Response. Washington, D.C: American Petroleum Institute.

[5] Use of absorbent materials in oil spill response, [23.03.2014, on-line] http:// www.itopf.com/information - services/publications/documents/TIP8UseofSorbent MaterialsinOilSpillResponse.pdf.

[6] [6] Lim T., Huang X., Evaluation of kapok (Ceiba pentandra (L.) Gaertn.) as a natural hollow hydrophobic-oleophilic fibrous sorbent for oil spill cleanup, Chemosphere 66 (2007) 955-963.

[7] Nanotechnology-based solutions for oil spills, [23.03.2014, on-line] http://www.nanowerk.com/spotlight/spotid=20215.php.

[8] Rajakovic V., Aleksic G., Radetic M., Rajakovic Lj., Efficiency of oil removal from real wastewater with different sorbent materials, Journal of Hazardous Materials 143 (2007) 494-499.

[9] Rajakovic-Ognjanovic V., Aleksic G., Lj. Rajakovic Lj., Governing factors for motor oil removal from water with different sorption materials, Journal of Hazardous Materials 154 (2008) 558-563.

[10] Arbatan T., Fang X., Shen W., Superhydrophobic and oleophilic calcium carbonate powder as a selective oil sorbent with potential use in oil spill clean-ups, Chemical Engineering Journal 166 (2011) 787-791.

[11] Gu J., Wei J., Wang F., Chen M., Mao J., Tan Xie T., Facile removal of oils from water surfaces through highlyhydrophobic and magnetic polymer nanocomposites, Applied Surface Science 301 (2014) 492-499. 
[12] Cojocaru C., Macoveanu M., Cretescu I., Peat-based sorbents for the removal of oil spills from water surface: Application of artificial neural network modeling, Colloids and Surfaces A: Physicochem. Eng. Aspects 384 (2011) 675- 684.

[13] Dutta P., Dass N., Chowdhury D., Sarma N., Oil-sorbent to hydrosorbent switching in Poly-9-octadecenylacrylate and Poly-9-octadecenylacrylate/Au nanocomposites, Chemical Engineering Journal 225 (2013) 202-209. 